\title{
Narrative Construction of Popularity Assessment Criteria on Weblogs: The Implications for Virtual Learning Environments
}

\author{
Cătălina-Ionela Rezeanu, ${ }^{1}$ Claudiu Coman, ${ }^{2}$ Angela Repanovici ${ }^{3}$ \\ ${ }^{1}$ Social Sciences and Communication, Transilvania University of Brasov, \\ Romania, rezeanucatalina@gmail.com \\ ${ }^{2}$ Social Sciences and Communication, Transilvania University of Brasov, \\ Romania, claudiu.coman@unitbv.ro \\ ${ }^{3}$ Product Design, Mechatronics and Environment, Transilvania University of Brasov, \\ Romania, arepanovici@unitbv.ro
}

\begin{abstract}
Scholars draw more and more attention on the benefits of using blogs as virtual learning environments. Because the period 2006 - 2007 was related in Romania to the emergence and unprecedented growth of blogs, we conducted a narrative analysis of online data, obtained during this period for the most popular Romanian blogs. By applying a qualitative-constructivist analysis of narrative data, we evidenced 5 popularity assessment criteria: (1) originality; (2) usefulness; (3) topicality; (4) subjectivity; (5) and coherence. Building on the identified criteria, we formulated recommendations for making blogs more efficient as virtual learning environments.
\end{abstract}

Keywords: internet; blogs; blogosphere; e-learning; narrative analysis; teaching; virtual learning environments. 


\title{
Narrative Construction of Popularity Assessment Criteria on Weblogs: The Implications for Virtual Learning Environments
}

\author{
Cătălina-Ionela Rezeanu, ${ }^{1}$ Claudiu Coman, ${ }^{1}$ Angela Repanovici ${ }^{2}$ \\ ${ }^{1}$ Social Sciences and Communication, Transilvania University of Brasov, Romania \\ 2 Product Design, Mechatronics and Environment, \\ Transilvania University of Brasov, Romania
}

\section{Introduction}

Today's pupils and students are the first generations with digital socializing experience. This is why, when teachers request them to complete documenting activities, they will first call upon web sources and only after will they search physical libraries. ${ }^{1}$ The possibilities offered by digital socializing platforms, such as blogging, can help teachers supervise the documenting process and stimulate students ' reflexivity in choosing information. In the last decades, on the international level, there is a tendency for teachers to use blogging platforms to enhance the learning and teaching process. Some of these blogs are known, read, and commented upon in the international academic communities, contributing to the popularization of specialized knowledge among researchers, teachers, and students, as well as the outside public, helping in growing the prestige of discipline, universities, students, and teachers.

More recently, scholars have shown how blogs can enhance learning by: increasing learners motivation, information retention and engagement ${ }^{2}$, developing reading skills, ${ }^{3}$ stimulating collaboration, ${ }^{4}$ creating personally meaningful contexts for education. ${ }^{5}$ Blogbased learning recommendations were proposed to improve education mainly in the fields of: foreign languages, ${ }^{6}$ politics, ${ }^{7}$ business, ${ }^{8}$ or health. ${ }^{9}$ Halavais ${ }^{10}$ explained how blogging

\footnotetext{
1 A. C. Halavais, "Weblogs and collaborative web publishing as learning spaces," in The International Handbook of Virtual Learning Environments, ed. Joel Weiss, Jason Nolan, Jeremy Hunsinger and Peter Trifonas (Dordrecht: Springer NL, 2006), 1215-1235.

2 L. Noel, "Using blogs to create a constructivist learning environment," in Procedia-Social and Behavioral Sciences 174 (2015): 617-621.

${ }^{3}$ S. F. S. A. Fattah, "The Effectiveness of Using Blogs as an Independent Learning Tool to Develop Reading Skills for University Students," Journal of Education and Practice 7(32) (2016): 65-73.

${ }^{4}$ A. M. Marques, R. Krejci, S. W. M. Siqueira et al, "Structuring the discourse on social networks for learning: Case studies on blogs and microblogs," Computers in Human Behavior 29(2) (2013): 395-400.

${ }^{5}$ H.-I. Hwan-Ik and Y. L. Lee, "Exploring new potentials of blogs for learning: Can children use blogs for personal information management (PIM)?” British Journal of Educational Technology 45(5) (2014): 916-925.

${ }^{6}$ S.-T. A. Hung and H.-T. D. Huang, "Blogs as a learning and assessment instrument for Englishspeaking performance," Interactive Learning Environments 24(8) (2016): 1881-1894.

${ }^{7}$ S. Xu, "Research on Ideological and Political Education of Southwest Petroleum University Students in Micro Blog Era,"' Creative Education 7(2) (2016): 287-292.
} 
platforms can be useful for teachers in managing the educational activities. This way, the learning process becomes experience-based and decentralized, expanding outside the physical bounds of the classroom and transforming into an accessible medium for the outside public. So, in the author's view the blog can contribute to the democratization of knowledge access and the reduction of the asymmetric relationship between the student and the teacher. According to the cited author, when students involve themselves in generating content for the blog, the learning experience becomes more authentic and more aim-based, because the potential audience of blog posts is far more extensive than the exposure to traditional assignments. Through blogs, students can create their network of specialists and collaborators to help them in the learning process. Based on the same source, by posting the assignments on didactic blogs, teachers might lay the foundations for a student discussion platform aggregating students ' patterns of understanding the tasks. Furthermore, by actively participating in the understanding process, students develop the skill to approach experts, to ask for clarifications, or to work with peers to ease the application of the new information. The author concludes educational blogs can be an important step towards meeting the imperative of lifelong learning extended beyond the formal school environment.

There are also some attempts to identify specific factors that enhance learning through blogs (experiential learning, perceived self-efficacy, perceived usefulness; ${ }^{11}$ the use of entrydominant bloggers; ${ }^{12}$ frequency of interactions: the degree of visiting, remaining and utilising the $\left.\operatorname{blog}^{13}\right)$, although the literature on this topic is still scarce. Therefore, to have positive learning effects, blogs must be visited. Blog popularity is not simply attained by posting as it requires meeting a specific set of criteria regarding the digital medium and its audience. This is why, within this paper, we aim to find the main characteristics which a Romanian blog must have, to be considered popular. Based on the results of a narrative analysis, we have showed 5 such criteria: (1) originality; (2) utility; (3) topicality; (4) subjectivity; and (5) coherence; and formulated recommendations for making blogs more efficient as learning environments.

\section{Clarifying the concepts of blog and blogosphere}

A blog is a website updated with entries (posts), grouped by categories and displayed chronologically. The term weblog was introduced by Jorn Barger in 1997 by joining two words: the web referring to the Internet network and log, referring to logging. In 1999, Peter Merholz proposed using the shorter term of blog. Although the term blog or weblog is most often used, a series of partial synonyms have been introduced: the online journal,

\footnotetext{
8 Y.-S. Wang, C.-R. Li, C.-H. Yeh et al., "A conceptual model for assessing blog-based learning system success in the context of business education," The International Journal of Management Education 14(3) (2016): 379-387.

${ }^{9}$ K. Lien, A. Chin, A. Helman et al., "A Randomized Comparative Trial of the Knowledge Retention and Usage Conditions in Undergraduate Medical Students Using Podcasts and Blog Posts," Cureus 10(1) (2018).

${ }^{10}$ Halavais, "Weblogs and collaborative web publishing as learning spaces," 1215-1235.

11 J. E. Tang, T.-I. Tang and C.-H. Chiang, "Blog learning: effects of users' usefulness and efficiency towards continuance intention," Behaviour \& Information Technology 33(1) (2014): 36-50.

12 B. K. Pursel and H. Xie, "Patterns and Pedagogy: Exploring Student Blog Use in Higher Education." Contemporary Educational Technology 5(2) (2014): 96-109.

${ }^{13}$ T. Karvounidis, K. Chimos, S. Bersimis et al., "Evaluating Web 2.0 technologies in higher education using students' perceptions and performance," Journal of Computer Assisted Learning 30, no. 6 (2014): $577-596$.
} 


\section{Cătălina-Ionela Rezeanu et al.}

Narrative Construction of Popularity Assessment Criteria on Weblogs

the Internet $\log$, or the personal page. It has also been agreed upon using the term blogosphere for the blogging network (first used in 1999 by Brad L. Graham).

Even if they are similar to personal journals, blogs show some differences: ${ }^{14}$ the blog presents information in the order of the most recent posts; the blog is public, its content grows from one day to the next and is accessible in real-time to those who follow it; the blog provides readers with the opportunity to search their content for the exact information of interest. What separates a blog from a journal is the potential or actual link with other blogs, and possibility of setting up virtual communities and social networks. Another feature of blogs is the ease with which visitors can write comments on the posts they have read, thus turning them into discussion and debate platforms. Moreover, in a blog, time does not flow in one direction, as the author can always return over time and modify the posted information.

The blog offers an opportunity to tell a story in a mediated forum, to a potentially wide, distant, and invisible audience. Links to other pages and comments can become devices for the authors self-expression. Blogs create contexts to establish a personal voice, a categorical attitude or a clear motivation ${ }^{15}$. However structured, chaotic, or impersonal they may seem, online journals reflect an intimate portrait of their author that builds over time. Briefly, someone's blog can become a tool for impression management. As the blog interacts with the audience even when the author is not online, the virtual identity resources being the references and the connections with other users, the online environment, unlike the offline one, allows for better self-performing and greater control over information released to the public. ${ }^{16}$

The most important feature of the blog is that it is part of a network of other blogs. If blogs are published texts that contain the thoughts of certain authors, the blogosphere is a social phenomenon. Although young, the blogosphere has the potential to evolve into a self-contained public sphere by teaching readers to identify with someone different from them, recognize and respect the fundamental rights of everyone. ${ }^{17}$

\section{The magnitude of the blogosphere and the motivation to start a blog}

In the last decades, the number of blogs has been steadily rising. If, by 2004, there were about 5 million blogs, in 2005, there was an explosion of their number reaching up to 50 million. ${ }^{18}$ Currently, it is estimated that their number is past 150 million. ${ }^{19}$ In 2007 , the

\footnotetext{
${ }^{14}$ Carmen Holotescu, Emerging Technologies in Education. Conceiving and Building a Microblogging Platform for Formal and Informal Learning (Bucharest: Politehnica Publishing House, 2015).

15 B. Graham, "Why I Weblog," in We've Got Blog: How Weblogs Are Changing Our Culture, ed. John Rodzvilla (Cambridge, MA: Perseus Publishing, 2002).

16 Daniel Chandler, "Personal home pages and the construction of identities on the web," last modified March 7, 2014, http://visual-memory.co.uk/daniel/Documents/short/webident.html (accessed 10 April, 2018).

17 M. A. Froomkin, "Habermas@ discourse.net: Toward a critical theory of cyberspace," Harvard Law Review 116, no. 3 (2003): 749-873.

18 Jeremy Wright, Blog Marketing: The revolutionary new way to increase sales, build brand, and get exceptional results (Columbus: The McGraw-Hill Companies, 2006).

19 Brandon Gaille, "How Many Blogs are on the Internet," WPVituoso, November 20, 2013, https://www.wpvirtuoso.com/how-many-blogs-are-on-the-internet (accessed 10 April, 2018).
} 
Romanian blogosphere added over 20,000 blogs, ${ }^{20}$ in 2018, their number exceeded 95,000 , producing more than 160,000 posts per month and more than 110,000 comments. ${ }^{21}$

Recent studies have identified multiple individual motives supporting the idea of having a blog. In some acceptations, people blog for: ${ }^{22}$ (1) expressing creativity; (2) storing and sharing experiences with others; (3) keeping in touch with friends and family; (4) sharing skills and knowledge; (4) mobilizing others for civic actions or for entertainment; (5) storing resources and important information for oneself; (6) influencing others`ideas; (7) forming knowledge-networks; and (8) earning money. A more recent study concluded the main reasons why bloggers have decided to open a blog are ${ }^{23}$ : (1) to become freelancers; (2) to express their creativity; (3) to form an audience; (4) to teach others what they know; and (5) to earn more money.

\section{The potential of blogs to become virtual learning environments}

The exponents of the Personal Learning Environment approach, according to which learners control and manage their own learning activity (receiving support only for learning objectives, learning process management, and communication with the learning community) recommend the blog as a tool to ease its implementation ${ }^{24}$. By interacting through blogs with other learners, students can become guides in others learning process, setting the foundation for collaborative learning communities. Specifically, the blog can support students in explorative learning and reflection on learning activities, and teachers in supervising students` progress. ${ }^{25}$

In this regard, scholars proposed to ask students to do digital video reporting assignments uploaded to a blogging platform, as opposed to the usual written assignment ${ }^{26}$, or to comment on a minimum of three posts from their colleagues per week and encouraged them to respond consistently to the most recent blog comments ${ }^{27}$. Another proposed tactic was to appoint a student for each course assignment, to post the homework on the class blog 48 hours before the offline course and to ask the other students to post

20 "O analiză a blogosferei românești bazată pe RoBloggersSurvey 2007 [An analysis of Romanian blogosphere based on RoBloggersSurvey 2007]," Timsoft, last modified November 5, 2007, http://www.timsoft.ro/ejournal/analiza_ro_blogosfera2007.html (accessed 10 April, 2018).

21 "Despre ce volum de informații/audientă vorbim când spunem «Social Media din .ro»? [What volume of information/audience are we talking about when we say «Social Media fom .ro»?]," Zelist Monitor, last modified 2018, https://www.zelist.ro/monitor (accessed 10 April, 2018).

22 Lenhart and Fox, "Bloggers. A portrait of the internet's new storytellers."

23 "State of the Blogging Industry," ConvertKit, last modified 2017. https:// convertkit.com/reports/blogging (accessed 10 April, 2018).

24 M. A. Chatti, M. Jarke and M. Specht, "The 3P learning model," Journal of Educational Technology \& Society 13, no. 4 (2010): 74-85.

${ }_{25}$ M. Derntl and T. Mazzurana, "Case study on student blogs in a blended learning course," in Learning and Instruction in the Digital Age, ed. Michael Spector, Dirk Ifenthaler, Pedro Isaias, Kinshuk and Demetrios Sampson (New York: Springer US, 2010), 309-25.

${ }_{26} \mathrm{P}$. Willmot, M. Bramhall and K. Radley, "Using digital video reporting to inspire and engage students," The Higher Education Academy (2012): 1-7.

27 A. C. Halavais, "Blogging Course Texts: Enhancing Our Traditional Use of Textual Materials," in Learning Through Digital Media: Experiments in Technology and Pedagogy, ed. R. Trebor Scholz (New York: The Institute for Distributed Creativity, 2011), 16-24. 
comments on that post. ${ }^{28}$ This way, students can already prepare arguments to participate in offline discussions in the classroom. Similarly, scholars recommend students be offered 5 10 minutes at the end of each offline lesson to post their thoughts and progress on the subject, on their own personal blogs ${ }^{29}$. Such a task can stimulate students' independent and reflexive learning skills as blogs record dialogue through comments. According to the same source, another teaching task may be to ask students to use the blog to show progress of independent documenting activity before being exposed to lectures or research projects on a new topic. Moreover, requesting students to post and comment on photos on a dedicated blog can be a tactic to ease the transition from formal learning to informal one ${ }^{30}$. The author suggests the blog can become a useful tool for students to share experiences of discovering a new language or culture. A more advanced implemented strategy was to develop a mobile blogging system to create virtual student classes, giving them the opportunity to post comments from real life contexts ${ }^{31}$.

The unprecedented development of digital technologies over the last decades predicts the 21 st century will present a proliferation of formal and informal learning digital literacy. In this context, both teachers and students need to get acquainted with various digital platforms (including blogging) to develop their digital fluency. Therefore, using blogs as teaching tools is not easy, and can raise a number of issues caused by the lack of students and teachers familiarity with this communication platform. To surpass these limits, there is a need for: teaching objectives be transparent, pupils participate in their creation, and teachers take on the facilitator's role in the learning process $^{32}$. It is also desirable that, in certain virtual contexts, students to be allowed to choose discussion moderators or even blog administrators. Furthermore, the cited author emphasizes the importance of accommodating students with self-directed learning, to the detriment of traditional methods of problem solving and assessment. The author believes digital educational technologies are not a panacea, but they have the potential to form essential skills such as associating learning with dialogue and participation.

The next step after inserting blogging platforms in the teaching medium is to use more complex integration platforms. In this regard, Dietrich and Ippolito ${ }^{33}$ present the Blackboard teaching platform, which allows students to download texts, upload their assignments, post on discussion threads, and create assignment calendars, while teachers can give customized feedback on homework or record student presence. The cited authors advocate for The Pool, which allows for the creation of collaborative projects where the level and type of individual contribution can be set. Moreover, the platform separates the projects into three stages (intent, approach and relieves). In the first stage the students can discuss and vote for the most important project tasks that need to be carried out. After the

\footnotetext{
${ }^{28}$ M. Zer-Aviv, "When Teaching Becomes an Interaction Design Task. Networking the Classroom with Collaborative Blogs," in Learning Through Digital Media: Experiments in Technology and Pedagogy, ed. R. Trebor Scholz (New York: The Institute for Distributed Creativity, 2011), 35-44.

${ }^{29}$ Helena Gillespie, Helen Boulton, Alison Hramiak and Richard Williamson, Learning and teaching with virtual learning environments (Exeter: Learning Matters Ltd., 2007).

30 A. Kukulska-Hulme, "Learning Cultures on the Move: Where are we heading?" Educational Technology \& Society 13, no. 4 (2010): 4-14.

31 Y.-M. Huang, Y.-L. Jeng and T.-C. Huang, "An Educational Mobile Blogging System for Supporting Collaborative Learning," Journal of Educational Technology \& Society 12, no. 2 (2009): 163-75.

32 Halavais, "Weblogs and collaborative web publishing as learning spaces," 1215-1235.

33 Craig Dietrich and Jon Ippolito, "A Path towards Global Reach The Pool," in Learning Through Digital Media: Experiments in Technology and Pedagogy, ed. R. Trebor Scholz (New York: The Institute for Distributed Creativity, 2011), 273-282.
} 
last stage, students have the opportunity to assess different components of their colleagues' contributions numerically (concept, perception, and technical).

\section{Narrative construction of popularity criteria on blogs}

In Romania, in the period between 2006-2007 blogging had an unprecedented development. 2006 was considered the most important year for blogging in Romania, because: the number of blogs has tripled compared to the previous year, ${ }^{34}$ the first Romanian blogs award festival was held as well as the first Romanian conference about the personal branding built through blogs, and the Internetics digital communication festival introduced a special category of prizes devoted to personal blogs. Worthy of note is the 2007 initiative by the Olympiads of Communication student contest to introduce a special section for blogs.

We have conducted a narrative analysis of online data produced in the aforementioned period on the most popular Romanian blogs. We operationalized the popularity within the blogosphere by the following dimensions: (1) notoriety - the blogs mentioned by at least 5 respondents in the research "RoBloggerSurvey 2006"; (2) interactivity - the blogs with the biggest number of visitors' comments; (3) loyalty - blogs with large numbers of subscribers; and (4) efficiency - blogs nominated for the "RoBlogFest 2006" competition. Based on this operationalization, we identified the following data sources: research on Romanian blogs RoBloggers Survey 2006, where 46 popular blogs were identified; the Romanian Blogging Awards RoBlogFest 2006, where 19 blogs have been nominated in 7 categories (the most niche blog, the best-written blog, the most informative blog, the blog that makes you think, the most interesting / original blog and the best blog). At the same time, we used narratives from the "Heritage for Europe - Time Capsule" project (170 posts from $100 \mathrm{blogs}$ ), lasting from 5 December to 10 January 2007, with the purpose of collecting posts containing personal and/or collective memories. In this paper we used data and narrative analysis taken from an unpublished dissertation thesis ${ }^{35}$. We used the qualitative-constructivist analysis of the self-narratives. The analysis involves the gradual processing of data, by asking questions and responding to them based on content. To read and analyse a narrative from a constructivist perspective means to keep interpretation as close as possible to that of the narrators and their readers.

After coding the data, we highlighted 5 themes that represent the narrative construction of 5 popularity criteria on Romanian blogs: (1) originality; (2) utility; (3) topicality; (4) subjectivity; (5) and coherence. These are considered necessary by authors and their audiences for a blog to be considered popular. Originality has its source in subjectivity and utility. Genuine personal blogs featuring life experiences that are considered authentic, and also expert blogs that make a subjective selection of objective data are considered to be original by their audience. So, personal or professional experience act as originality criteria. This relation also works in reverse, and the utility is valued by subjectivity. In this particular case, a blog is interpreted as useful by its author. The usefulness is related to the fact that the content of a blog is perceived as useful if it meets the expectations of its audience. The greatest importance in interpreting a blog as popular is the impression of coherence it produces. The author of the blog should be able to integrate the originality, the subjectivity,

34 "O analiză a blogosferei românești bazată pe RoBloggersSurvey 2006 [An analysis of Romanian blogosphere based on RoBloggersSurvey 2006]," Timsoft, last modified August 20, 2006, http://www.timsoft.ro/ejournal/analiza_ro_blogosfera2006.html (accessed 10 April, 2018).

35 Cătălina.-Ionela Rezeanu, "The blog: personal branding, impression management, and narrative construction of the self in the virtual space" (unpublished PhD diss., University of Bucharest, 2007). 


\section{Cătălina-Ionela Rezeanu et al.}

Narrative Construction of Popularity Assessment Criteria on Weblogs

the usefulness and the topicality of the posted information into a coherent strategy. On the blog, consistency can be achieved in three ways: temporal coherence, causal coherence and thematic coherence. The temporal coherence means the connections among different information is made by their sequence in time, and it is often complemented by spatial placement. Causal coherence is based on the idea that the unity of a narrative can not only be linear but also branched by causal links. Thematic coherence refers to the selection of events around themes that overdo them.

Through its nature, the blog is a tool that facilitates all these five strategies. In the virtual environment, there is a pressure for bloggers to make creative productions as the competition and innovation are stronger. This online environment allows for creativity exercises as data about the others is fragmented and the lack of information is supplemented by imagination. In other words, it is much easier for the bloggers to be original by relying on what makes its audience imagine about them. The impression of subjectivity gets new valences on the blog. With its facilities, the blog encourages constant information updating. First, the blog sorts the information so that the most recent post is always on the first page. Then, in a typical blog, there is a calendar view of the data to which posts have been added. By being able to group information into categories, the blog allows the manifestation of utility and subjectivity. The categories that most blogs authors use are "useful" and "personal". In addition, by placing the blog in one of the already known classifications (personal or niche) allows the reader to catalogue the type of information in it (subjective or useful). Archiving all blog posts as well as the existence of search engines that search for information based on keywords are ways of facilitating the utility. In an online journal, coherence becomes a legitimacy criterion. Since in the virtual environment there is no possibility of verifying the discourse by confronting it with nonverbal language, the veracity of the information is assessed by the impression of coherence and the absence of contradictions.

\section{Implications for the field of education}

Applying the suggestions formulated in the literature to materialise the potential of blogs to become virtual learning platforms is necessary, but not sufficient. The research presented above suggests, to be visited, known, and appreciated, blogs are required to meet particular assessment criteria (originality, subjectivity, topicality, utility, and coherence).

To meet the originality criteria, educational blogs should not duplicate the information that students already have access to, but encourage their original syntheses (selection of concepts, theories, and methods considered by students as atypical or controversial) and passing them through the personal experience filter. Thus, teachers can ask students to read independently to find unconventional and counter-intuitive theories and methods of research. Moreover, students can use the blog to nuance the abstract information already learned with examples from their daily life, being stimulated to produce their own interpretations and even make changes to the established theories of the studied disciplines and topics. To create an environment that stimulates the production of innovative ideas, teachers can give appraisal rewards to students who actively participate in comments on blog posts, motivating them to post their own interpretations of interpretations written by their peers. Also, an educational blog should be managed by a prestigious teacher, with most of the posts being uploaded by students on themes that illustrate innovative theories with authentic daily life experiences. The fact that the blog is compatible with multimedia content, publishing facilities can ease the originality strategy. In this regard, one could use the recommendation to give students assignments that they can solve by blogging their photo reports or by responding to comments on teacher-uploaded content. 
Applying the criterion of subjectivity, educational blogs should rely on creating the impression of authenticity. In particular, such blogs should not mimic the teaching materials used in the course, but instead tune them through the subjective-interpretive narratives of the students. In this way, visiting such a blog would create an experience similar to exposure to a documentary on a specialist topic. Blogs could be used by teachers to train students in using the theoretical and methodological tools of disciplines, to analyse their own life experiences, and to become aware of their own progress in the learning process. For instance, the experience of international mobility may be an opportunity to ask students to share this situation with their colleagues by constantly posting to a dedicated section of the blog (both about the theoretical content they were exposed to and about the academic or specific cultural process from the new context). Not just international mobility, yet their own learning path (with upsides, downsides, or difficulties) can also be a pretext for selfanalysis on the blog. Teachers could ask students to post monthly personal observations on their individual documenting process, or to post at the end of each course session, sharing personal reactions and informed changes relative to the subjective understanding of the taught subject. Especially for Social Science students, the educational blog can be a platform where they can upload their own research journal, posting observations, difficulties, subjective impressions filled using audio, photo, or video content (interviews, mental maps, research routes, etc.). Respecting the criterion of subjectivity in operating blogs as educational platforms could contribute to the formation of students' abilities for reflexivity and critical thinking, being an important step towards encouraging self-directed learning and the democratization of access to knowledge. By encouraging students to appropriate the assimilated didactic content, the impression of authenticity they transmit the audience could improve the image of higher education.

To meet the utility and topicality criteria, educational blogs should be more similar to specialized blogs (niche) managed by credible personalities in the field. That is why it is important for well-known teachers and professionals being visible on these blogs to give credibility to posted content. On the one hand, such blogs need to be coordinated by teachers and, on the other hand, must include guest posts from well-known specialists in the field. In the latter case, teachers can use the widely spread AMA (Ask Me Anything) or Q \& A (Question \& Answer) tactics in which a celebrity in the field responds through blog comments to questions posed by students. To build an educational blog with useful and upto-date content, teachers might post links to news about recent events of great interest (from the socio-political-economic realm) asking students to comment on them using their theoretical-methodological tools from their domain of study. In turn, students can be encouraged to search for and post news about the latest research in their field of study, which can become pretexts for online discussions using comments or video-conferences.

To be considered coherent, educational blogs should be managed by a teacher to make sure the content is integrated through a unitary approach. A first tactic might be to narrow the content of the blog to a thematic area (for instance, in the field of sociology, blogs, such as, Sociological Images, Sociological Cinema or Creativity via Sociology) are relatively popular. Another strategy could be for a teacher to moderate comments, guiding the debate, to ensure students' arguments are consistent. In this regard, it is also recommended assigning a student for each theme, who will post their homework on the blog 48 hours before the offline lesson on that particular theme, and ask the other students to comment on the post, to ensure consistency between the content of the offline course and the online blog; also, asking students to use the blog to advance their independent reading activity before being exposed to lectures or research projects on a new topic could help shape a coherent strategy of self-directed learning. The temporal or spatial consistency can be ensured by classifying blog content by space-time criteria. Narrative time coherence can be 


\section{Cătălina-Ionela Rezeanu et al.}

Narrative Construction of Popularity Assessment Criteria on Weblogs

sustained by imposing on the students a certain frequency of subjective content posting on the blog. Causal consistency can be maintained by regularly organizing blog discussions where students are encouraged to find causal links among different contents. To ensure thematic consistency, it is important for the teacher to post blog pages that thematically classify information and update them regularly. Based on these debates and synthesis pages, the blog administrator should constantly insert hyperlinks that causally link old and new content and revise tags to consistently optimize the classification of information.

\section{Conclusions}

In a context in which national policies were launched forbidding the use of mobile phones during classrooms to reduce the propensity to access new media, we stand for a different approach. We consider that even a simple and longstanding interactive platform such as the blogging one has potential to enrich the future of learning in formal educational institutions. Since the research presented revealed that the five narrative criteria of blog popularity function interdependently, the criterion of consistency being the most important, the next step, after using blogs as digital educational environments, is the adoption of complex integrative educational platforms.

Although we live in a time when information can be instantly accessed almost anywhere and at any time and young generations are the early adopters of new technologies and new media, the literature on their potential to enhance education in formal institutions is still scarce. By using a narrative-constructivist approach in analysing blogs, and taking a personal learning environment perspective in formulating teaching recommendations, this paper tries to fill this gap. It pleads for the need to consider particular contextual popularity criteria (originality, utility, topicality; subjectivity, and coherence) in order to activate the positive effects of blogs as virtual learning environments.

The results can inspire practitioners in field of formal education in planning teaching activities and formulating assignments for students. For researchers, they can be useful both as a methodological tool to assess popularity in the blogosphere and as a source of hypotheses about the dimensions of popularity that influence learning. To surpass the limitations of this study (lack of generalizability of qualitative results, secondary analysis of not very recent data), future research could orient towards testing the mediation effects of the identified criteria on the positive influence of blogs on education, by applying advanced quantitative analyses on representative samples collected from blogs that are popular in the present time.

\section{References}

"Despre ce volum de informatii/audientă vorbim când spunem «Social Media din .ro»? [What volume of information/audience are we talking about when we say «Social Media from .ro»?]." Zelist Monitor. Last modified 2017. https://www.zelist.ro/monitor (accessed 10 April, 2018).

“O analiză a blogosferei românești bazată pe RoBloggersSurvey 2007. [An analysis of Romanian blogosphere based on RoBloggersSurvey 2007.]" Timsoft. Last modified November 5, 2007 http://www.timsoft.ro/ejournal/analiza_ro_blogosfera2007.html (accessed 10 April, 2018).

“O analiză a blogosferei românești bazată pe RoBloggersSurvey 2006. [An analysis of Romanian blogosphere based on RoBloggersSurvey 2006.]" Timsoft. Last modified August 20, 2006. http://www.timsoft.ro/ejournal/analiza_ro_blogosfera2006.html (accessed 10 April, 2018). 
"State of the Blogging Industry." ConvertKit. Last modified 2017. https://convertkit.com/reports/blogging (accessed 10 April, 2018).

"State of the Blogosphere 2010." Technocrati. Last modified 2010. http://technorati.com/state-of-the-blogosphere-2010.

Chandler, Daniel. "Personal home pages and the construction of identities on the web." Last modified March 7, 2014. http://visualmemory.co.uk/daniel/Documents/short/webident.html (accessed 10 April, 2018).

Chatti, Mohamed Amine, Matthias Jarke, and Marcus Specht. "The 3P learning model." Journal of Educational Technology \& Society 13, no. 4 (2010): 74-85.

Derntl, Michael, and Thomas Mazzurana. "Case study on student blogs in a blended learning course." In Learning and Instruction in the Digital Age edited by Michael Spector, Dirk Ifenthaler, Pedro Isaías, Kinshuk, and Demetrios Sampson, 309-25. New York: Springer US, 2010.

Dietrich, Craig., and Jon Ippolito. "A Path towards Global Reach The Pool.” In Learning Through Digital Media: Experiments in Technology and Pedagogy edited by R. Trebor Scholz, 273-82. New York: The Institute for Distributed Creativity, 2011.

Fattah, Said Fathy El Said Abdul. "The Effectiveness of Using Blogs as an Independent Learning Tool to Develop Reading Skills for University Students." Journal of Education and Practice 7, no. 32 (2016): 65-73.

Froomkin, A. Michael. "Habermas@ discourse. net: Toward a critical theory of cyberspace." Harvard Law Review 116, no. 3 (2003): 749-873.

Gaille, Brandon. "How Many Blogs are on the Internet." Last modified 2014. https://www.wpvirtuoso.com/how-many-blogs-are-on-the-internet (accessed 10 April, 2018).

Gillespie, Helena., Helen Boulton, Alison Hramiak, and Richard Williamson. Learning and teaching with virtual learning environments. Exeter: Learning Matters Ltd., 2007.

Graham, Brad. "Why I Weblog”. In We've Got Blog: How Weblogs Are Changing Our Culture edited by John Rodzvilla, 34-40. Cambridge, MA: Perseus Publishing, 2002.

Halavais, Alexander C. "Blogging Course Texts: Enhancing Our Traditional Use of Textual Materials." In Learning Through Digital Media: Experiments in Technology and Pedagogy edited by R. Trebor Scholz (16-24). New York: The Institute for Distributed Creativity, 2011.

Halavais, Alexander C. "Weblogs and collaborative web publishing as learning spaces." In The International Handbook of Virtual Learning Environments edited by Joel Weiss, Jason Nolan, Jeremy Hunsinger, and Peter Trifonas, 1215-35. Dordrecht: Springer NL, 2006.

Holotescu, Carmen. Emerging Technologies in Education. Conceiving and Building a Microblogging Platform for Formal and Informal Learning. Bucharest: Politehnica Publishing House, 2015.

Huang, Yueh-Min, Yu-Lin Jeng, and Tien-Chi Huang. "An Educational Mobile Blogging System for Supporting Collaborative Learning". Journal of Educational Technology \& Society 12, no. 2 (2009): 163-75.

Hung, Shao-Ting Alan and Heng-Tsung Danny Huang. "Blogs as a learning and assessment instrument for English-speaking performance." Interactive Learning Environments 24, no. 8 (2016): 1881-1894.

Lien, Kelly, Alvin Chin, Anton Helman, and Teresa M. Chan. "A Randomized Comparative Trial of the Knowledge Retention and Usage Conditions in Undergraduate Medical Students Using Podcasts and Blog Posts." Cureus 10, no. 1 (2018).

Karvounidis, Theodoros, Konstantinos Chimos, Sotiris Bersimis, and Christos Douligeris. "Evaluating Web 2.0 technologies in higher education using students' perceptions and performance." Journal of Computer Assisted Learning 30, no. 6 (2014): 577-596.

Kukulska-Hulme, Agnes. "Learning Cultures on the Move: Where are we heading?" Educational Technology \& Society 13, no. 4 (2010): 4-14. 
Lenhart, Amanda, and Susannah Fox. "Bloggers. A portrait of the internet's new storytellers." Pew Internet \& American Life Project. Last modified July 19, 2006. http://www.pewtrusts.org/ /media/legacy/uploadedfiles/wwwpewtrustsorg/reports/ society_and_the_internet/PIPBloggers071906pdf.pdf (accessed 10 April, 2018).

Marques, Aline M., Rafael Krejci, Sean WM Siqueira, Mariano Pimentel, and Maria Helena LB Braz. "Structuring the discourse on social networks for learning: Case studies on blogs and microblogs." Computers in Human Behavior 29, no. 2 (2013): 395-400.

Noel, Lindsay. "Using blogs to create a constructivist learning environment." Procedia-Social and Behavioral Sciences 174 (2015): 617-621.

Pursel, Barton K. and Hui Xie. "Patterns and Pedagogy: Exploring Student Blog Use in Higher Education." Contemporary Educational Technology 5, no. 2 (2014): 96-109.

Rezeanu, Cătălina.-Ionela. "The blog: personal branding, impression management, and narrative construction of the self in the virtual space." PhD diss., University of Bucharest, 2007.

Tang, Jeung-tai E., Tzung-I. Tang, and Chi-Hui Chiang. "Blog learning: effects of users' usefulness and efficiency towards continuance intention." Behaviour \& Information Technology 33, no. 1 (2014): 36-50.

Wang, Yi-Shun, Ci-Rong Li, Ching-Hsuan Yeh, Shin-Tzu Cheng, Chei-Chang Chiou, YuCheng Tang, and Tzung-I. Tang. "A conceptual model for assessing blog-based learning system success in the context of business education." The International Journal of Management Education 14, no. 3 (2016): 379-387.

Willmot, Peter, Mike Bramhall, and Keith Radley. "Using digital video reporting to inspire and engage students." The Higher Education Academy (2012): 1-7.

Wright, Jeremy. Blog Marketing: The revolutionary new way to increase sales, build brand, and get exceptional results. Columbus: The McGraw-Hill Companies, 2006.

$\mathrm{Xu}$, Shasha. "Research on Ideological and Political Education of Southwest Petroleum University Students in Micro Blog Era." Creative Education 7, no. 02 (2016): 287-292.

Yeo, Hwan-Ik and Yekyung Lisa Lee. "Exploring new potentials of blogs for learning: Can children use blogs for personal information management (PIM)?.” British Journal of Educational Technology 45, no. 5 (2014): 916-925

Zer-Aviv, Mushon. "When Teaching Becomes an Interaction Design Task. Networking the Classroom with Collaborative Blogs." In Learning Through Digital Media: Experiments in Technology and Pedagogy edited by R. Trebor Scholz, 35-44. New York: The Institute for Distributed Creativity, 2011. 